\title{
Jumlah semut Myopopone castaneae (Hymenoptera:Formicidae) yang dihasilkan dengan pakan berbagai instar larva Oryctes rhinoceros L. (Coleoptera: Scarabaidae) di laboratorium
}

Number of ants Myopopone castaneae (Hymenoptera: Formicidae) generated by feeding the various instar larvae Oryctes rhinoceros L. (Coleoptera: Scarabaidae) in the laboratory

Irena Santy Waruwu, Marheni*, Lahmuddin Lubis

Program Studi Agroteknologi, Fakultas Pertanian USU, Medan 20155

*Corresponding author: marheni.sembiring@yahoo.com

\section{ABSTRACT}

Ants of Myopopone castaneae (Hymenoptera: Formicidae) is a one potential predators of larvae palm stem borer Oryctes rhinoceros L. (Coleoptera: Scarabidae). These ants are able to prey on all stadia of larvae $O$. rhinoceros $L$. This research was aimed to know the number of ants Myopopone castaneae (Hymenoptera: Formicidae) generated by feeding the various instar larvae of palm stem borer Oryctes rhinoceros L. (Coleoptera: Scarabaidae) in the laboratory. The research was conducted at Laboratory of Plant Pest, Faculty of Agriculture, University of Sumatera Utara from April until September 2017. This research used nonfactorial Randomize Completely Design with 3 treatments and 6 replications. The results showed that various instar larvae O. rhinoceros was significantly different to number of ants generated. The highest number of ants was instar I (0,67 queen ants, 2,17 male ants, and 68 working ants) dan the lowest number of ants was instar III (0 queen ant, 0 male ant and 65,83 working ant). The highest consumption was instar I (130,17 ants) and lowest one was instar III (73,83 ants). There were three types of ants in colony including queen, male and working ants.

Keywords: Myopopone castaneae, Oryctes rhinoceros, palm stem borer, predator

\begin{abstract}
ABSTRAK
Semut Myopopone castaneae (Hymenoptera: Formicidae) merupakan salah satu predator yang potensial untuk larva Oryctes rhinoceros L. (Coleoptera: Scarabidae). Semut ini dapat memangsa berbagai stadia larva $O$. rhinoceros $L$. Penelitian ini bertujuan untuk mengetahui jumlah semut Myopopone castaneae (Hymenoptera:Formicidae) yang dihasilkan dengan pakan berbagai instar larva penggerek pucuk kelapa sawit Oryctes rhinoceros L. (Coleoptera: Scarabaidae) di laboratorium. Penelitian dilaksanakan di Laboratorium Hama Tumbuhan, Fakultas Pertanian, Universitas Sumatera Utara mulai bulan April sampai September 2017. Penelitian menggunakan Rancangan Acak Lengkap (RAL) nonfaktorial dengan 3 perlakuan dan 6 ulangan. Hasil penelitian menunjukkan pemberian pakan larva Oryctes rhinoceros berpengaruh nyata terhadap jumlah semut yang dihasilkan. Jumlah semut tertinggi pada perlakuan instar I (0,67 ekor ratu, 2,17 ekor jantan dan 68 ekor pekerja) dan terendah instar III (0 ekor ratu, 0 ekor jantan dan 65,83 ekor pekerja). Daya konsumsi tertinggi terdapat pada perlakuan instar I (130,7 ekor) dan terendah instar III (73, 83 ekor). Semut yang dihasilkan dalam koloni ada tiga jenis yaitu semut ratu, semut jantan dan semut pekerja.
\end{abstract}

Kata kunci: Myopopone castaneae, Oryctes rhinoceros, larva penggerek pucuk kelapa sawit, predator 


\section{PENDAHULUAN}

Tanaman kelapa sawit (Elaeis guineensis Jacq.) merupakan tanaman asli Nigeria, Afrika Barat meskipun sebagian mengatakan berasal dari Brazilia karena spesies kelapa sawit banyak ditemukan di hutan Brazilia. Meskipun demikian tanaman kelapa sawit dapat tumbuh subur di luar negara asalnya seperti Indonesia, Malaysia, Papua Nugini dan Thailand (Lumbangaol, 2007).

Berbagai faktor dapat menyebabkan produksi kalapa sawit menurun. Salah satu faktor tersebut adalah serangan hama tanaman. Serangan hama ini di areal kelapa sawit dapat menimbulkan kerugian apabila tidak dikelola dengan baik (Noprida, 2009).

Hama kumbang tanduk (Oryctes rhinoceros L.) merupakan salah satu hama yang menyerang pertanaman kelapa sawit. Umumnya menyerang tanaman kelapa sawit yang muda. Kumbang $O$. rhinoceros menggerek pucuk tanaman dan menyebabkan kerusakan di sekitar titik tumbuh, sehingga kerap kali menyebabkan malformasi pada pupus. Pada areal serangan berat, hampir semua tanaman diserang oleh kumbang ini, bahkan satu tanaman dapat digerek beberapa kali, sehingga dapat menyebabkan kematian tanaman (Purba, 2010).

Serangan hama ini dapat menurunkan produksi tandan buah segar (TBS) pada tahun pertama hingga $69 \%$ dan menimbulkan kematian pada tanaman muda hingga $25 \%$. Masalah kumbang tanduk saat ini semakin bertambah dengan adanya aplikasi tandan kosong pada kelapa sawit yaitu pada gawangan maupun pada sistem lubang tanam besar (BPKKS, 2014).

Pengendalian hayati merupakan salah satu metode pengendalian hama yang diminati akhir- akhir ini karena memiliki keunggualan. Diantaranya adalah sifatnya yang ramah lingkungan, dapat menghemat biaya dan diharapkan dapat mencegah peledakan populasi hama (Susilo, 2007).

Terdapat sekitar 1.000 .000 spesies serangga dibumi ini, termasuk spesies-spesies serangga yang menjadi musuh alam. Ditaksir baru $15 \%$ dari seluruh spesies serangga musuh alam yang ditemukan dan diidentifikasi. Musuh-musuh alam yang mewakili dunia serangga dapat digolongkan menjadi dua yaitu predator dan parasitoid (Oka, 2015).

Beberapa spesies musuh alami yang pernah diintroduksikan ke Malaysia dalam menekan perkembangan hama $O$. rhinoceros adalah Scolia ruficornis (Hymenoptera: Scoliidae), Platymeris laevicolis Distant (Hemiptera: Reduviidae), Holoeptra quadriedentata (Fabricius) (Coleoptera: Histeridae) dan Pyrophorus sp. (Coleoptera : Elateridae) (Chong, 2011).

Penemuan musuh alami Myopopone castaneae, Cheiroseius sp., Trigonuropoda sp dan Hypoaspis krameri (Canestrini) sebagai agen hayati $O$. rhinoceros merupakan hasil penelitian terbaru atau belum ada penelitian dan penemuan sebelumnya (Marheni, 2012).

Semut My. castanea (Hymenoptera: Formicidae) merupakan predator untuk larva O. rhinoceros (Marheni, 2012). Semut ini memakan larva bahkan pupa $O$. rhinoceros. Semut predator ini dikenal sebagai predator obligat terhadap arthropoda, dan mencari makan di tanah, sampah daun atau kayu yang membusuk. Predator ini menyerang mangsanya dalam keadaan yang masih hidup dengan cara menyengat dan menggigitnya hingga mati, lalu menghisap cairan hemolimfnya sampai tinggal bagian kutikulanya saja bahkan dapat memakan tubuh larva (Junaedi, 2014).

Di Perkebunan kelapa sawit, semut $M y$. castaneae bisa ditemukan di batang-batang sawit yang tumbang dan sudah melapuk karena sudah tua ataupun karena penyakit busuk pangkal batang. Larva $O$. rhinoceros di perkebunan kelapa sawit biasanya juga hidup di batang-batang kelapa sawit yang melapuk dan di tumpukan bahan organik. Adanya kesamaan relung tempat hidup antara semut dan larva $O$. rhinoceros membuka peluang yang besar untuk memanfaatkan semut predator ini sebagai agens hayati yang potensial untuk hama $O$. rhinoceros (Widihastuty,dkk, 2017). 


\section{BAHAN DAN METODE}

Penelitian dilaksanakan di Laboratorium Hama Tumbuhan Universitas Sumatera Utara, Medan. Dengan ketinggian tempat $+25 \mathrm{~m}$ di atas permukaan laut. Penelitian dilaksanakan pada bulan April sampai September 2017.

Adapun bahan yang digunakan dalam penelitian ini adalah semut My. castaneae, larva $O$. rhinoceros instar satu, dua, dan tiga, batang kelapa sawit, air, tisu serta bahan pendukung lainnya. Alat-alat yang digunakan adalah kotak kaca ukuran 40×20×20 cm, kain kasa, karet, kertas label, kuas, kamera, alat tulis serta alat pendukung lainnya.

Penelitian menggunakan Rancangan Acak Lengkap (RAL) non faktorial, dengan 3 perlakuan yaitu Instar I : Semut $M y$. castaneae dengan pakan larva instar satu $O$. rhinoceros L.. Instar II :Semut My. castaneae dengan pakan larva instar dua $O$. rhinoceros L., Instar III :Semut My. castaneae dengan pakan larva instar tiga $O$. rhinoceros $\mathrm{L}$.

Pelaksanaan penelitian dimulai dengan persiapan media perlakuan. Media yang digunakan berupa kotak kaca ukuran $40 \times 20 \times 20 \mathrm{~cm}$ yang telah diisi dengan makanan $O$. rhinoceros L. yaitu berupa serbuk dari batang kelapa sawit yang telah membusuk yang diambil dari lapangan. Bersama dengan kotak kaca disediakan juga kain kasa dan karet yang digunakan untuk menutup bagian atas kotak kaca. Kemudian Semut My. castaneae diambil dari lapangan sebanyak-banyaknya dari batang kelapa sawit yang telah melapuk pada areal penanaman kelapa sawit. Semut kemudian di bawa ke laboratorium untuk dipelihara dalam beberapa kotak kaca yang sudah berisi batang kelapa sawit, beserta pakan semut berupa larva $O$. rhinoceros L. Larva $O$. rhinoceros diambil dari lapangan sebanyak banyaknya yang sehat terdiri dari larva instar satu, larva instar dua, dan larva instar tiga. Semut dipelihara dengan menggunakan kotak kaca dengan meletakkan koloni semut berupa ratu semut, semut kasta prajurit, kasta pekerja, batang kelapa sawit beserta pakan semut berupa larva O. rhinoceros L. setiap satu kurungan kaca diletakkan 1 koloni semut (1 semut ratu, 5 semut jantan dan 70 semut pekerja). Kelembaban didalam kurungan kaca tetap dijaga dengan menyemprotkan air pada batang sawit secukupnya. Pemberian pakan berupa larva $O$. rhinoceros L. dilakukan setiap 3 hari dengan mengaplikasikan 5 larva $O$. rhinoceros L. untuk perlakuan instar I, 4 larva $O$. rhinoceros $\mathrm{L}$ untuk perlakuan instar II dan 3 larva $O$. rhinoceros $\mathrm{L}$ untuk perlakuan instar III ke dalam kotak kaca.

Peubah amatan terdiri dari jumlah semut My. castaneae yang dihasilkan dari setiap perlakuan, perhitungan jumlah semut yang dihasilkan dilakukan dengan mengamati dan menghitung jumlah semut baru yang terbentuk pada setiap perlakuan serta diamati berapa jumlah ratu, jantan serta pekerja. Daya konsumsi semut My. castaneae terhadap larva $O$. rhinoceros L., pengamatan daya konsumsi semut $M y$. castaneae terhadap larva $O$. rhinoceros L. dilakukan dengan menghitung jumlah larva $O$. rhinoceros L. yang dapat dimangsa sampai membentuk semut baru. Morfologi anggota semut My. castaneae yang dihasilkan, pengamatan morfologi anggota semut My. castaneae dilakukan dengan mengamati ciri-ciri semut baik berupa semut ratu, jantan maupun pekerja pada setiap koloni yang terbentuk.

\section{HASIL DAN PEMBAHASAN}

\section{Jumlah semut My. castaneae yang dihasilkan dari setiap perlakuan}

Hasil pengamatan terhadap jumlah semut yang dihasilkan pada setiap perlakuan dapat dilihat pada Tabel 1 .

Tabel 1. Jumlah semut My. castaneae yang dihasilkan dari setiap perlakuan

\begin{tabular}{lccc}
\hline \multirow{2}{*}{ Perlakuan } & \multicolumn{3}{c}{ Rataan Semut (Ekor) } \\
\cline { 2 - 4 } & Ratu & Jantan & Pekerja \\
\hline Instar I & $0,67 \mathrm{~b}$ & $2,17 \mathrm{~b}$ & $68,00 \mathrm{~b}$ \\
Instar II & $0,17 \mathrm{a}$ & $0,83 \mathrm{a}$ & $69,33 \mathrm{~b}$ \\
Instar III & $0,00 \mathrm{a}$ & $0,00 \mathrm{a}$ & $65,83 \mathrm{a}$ \\
\hline Keterangan: & $\begin{array}{c}\text { Angka yang diikuti notasi } \\
\text { pada }\end{array}$ \\
\multicolumn{4}{c}{ kolom berbeda } \\
berbeda nyata pada taraf 5 \% & menunjukkan \\
\end{tabular}

Hasil analisa sidik ragam perhitungan jumlah semut yang dihasilkan pada Tabel 1 
dapat diketahui bahwa pemberian pakan larva instar I berbeda nyata terhadap jumlah semut ratu yang dihasilkan dengan pemberian pakan larva instar II dan IIII. Jumlah semut ratu tertinggi yaitu pada perlakuan instar I sebesar 0,67 ekor dan terendah terdapat pada perlakuan instar III sebesar 0,00 ekor. Pada semut jantan pemberian pakan larva instar I dan II berbeda nyata terhadap jumlah semut jantan yang dihasilkan pada perlakuan pemberian pakan larva instar III. Perlakuan tertinggi yaitu terdapat pada perlakuan instar I sebesar 2,17 ekor kemudian terendah instar III yaitu 0,00 ekor. Pada semut pekerja pemberian pakan larva instar I dan instar II berbeda nyata terhadap jumlah semut pekerja yang dihasilkan dengan pemberian pakan larva Instar III. Perlakuan tertinggi yaitu terdapat pada perlakuan instar II sebesar 69,33 ekor pekerja kemudian terendah instar III yaitu 65,83 ekor pekerja.

Hasil analisa sidik ragam perhitungan jumlah semut yang dihasilkan dapat diketahui bahwa pemberian pakan larva instar I, II dan III berpengaruh nyata terhadap jumlah semut yang dihasilkan. Hal ini dikarenakan adanya perbedaan nutrisi pada masing-masing pakan larva $O$. rhinoceros L. instar I, II dan III, sehingga jumlah semut yang dihasilkan juga berbeda. Hal ini sesuai dengan Hagen (2016) yang menyatakan bahwa perbedaan kualitas dan kuantitas mangsa mempengaruhi kebugaran predator. Mangsa mangsa yang berkualitas bagi predator adalah yang memiliki komposisi nutrisi dan unsur penting (energi, nutrisi, dan toksin) yang mirip satu sama lain sehingga dapat dijadikan sebagai kisaran mangsanya.

Hasil analisa sidik ragam perhitungan jumlah semut yang dihasilkan dapat diketahui jumlah semut tertinggi terdapat pada perlakuan dengan pakan instar I Ratu 0,67 ekor, jantan 2,17 ekor dan pekerja 68,00 ekor. Kemudian diikuti perlakuan instar II yaitu Ratu 0,17 ekor, jantan 0,83 ekor dan pekerja 69,33 ekor. Sedangkan jumlah semut terendah adalah pada perlakuan dengan pakan instar 3 yaitu dengan rataan semut Ratu 0 ekor, jantan 0 ekor dan pekerja 65,83 ekor. Perbedaan ini dikarenakan perbedaan nutrisi yang terdapat pada masing-masing pakan larva instar I, II dan III yang menyebabkan perbedaan pada jumlah dan anggota semut yang dihasilkan. Hagen (2016) menyatakan bahwa predator memerlukan mangsa dengan nutrisi yang berbeda sesuai dengan kebutuhan untuk perkembangbiakannya.

\section{Daya konsumsi semut My. castaneae terhadap larva $O$. rhinoceros $\mathrm{L}$.}

Hasil pengamatan daya konsumsi semut $M y$. castaneae terhadap larva $O$. rhinoceros $\mathrm{L}$ dapat dilihat pada Tabel 2.

Tabel 2. Daya konsumsi semut My. castaneae terhadap larva $O$. rhinoceros $\mathrm{L}$.

\begin{tabular}{lc} 
Perlakuan & Rataan (Ekor) \\
\hline Instar I & $130,17 \mathrm{c}$ \\
Instar II & $108,17 \mathrm{~b}$ \\
Instar III & $73,83 \mathrm{a}$ \\
\hline
\end{tabular}

Keterangan: Angka yang diikuti notasi yang berbeda pada kolom yang sama menunjukkan berbeda nyata pada taraf $5 \%$ pada uji BNT.

Dari hasil pengamatan daya konsumsi semut My. castaneae terhadap larva $O$. rhinoceros $\mathrm{L}$ dapat diketahui bahwa daya konsumsi semut pada larva instar I dan II berbeda nyata dengan larva instar III. Daya konsumsi tertinggi terdapat pada perlakuan dengan pakan larva $O$. rhinoceros $\mathrm{L}$ instar I yaitu 130,17 ekor dan diikuti oleh perlakuan dengan pakan larva $O$. rhinoceros L instar II yaitu 108,17 ekor. Sedangkan daya konsumsi terendah terdapat pada perlakuan dengan pakan larva $O$. rhinoceros L instar III yaitu 73,83 ekor.

Dari hasil pengamatan daya konsumsi semut $M y$. castaneae terhadap larva $O$. rhinoceros $\mathrm{L}$ dapat diketahui bahwa daya konsumsi semut pada larva instar I, II dan III berbeda nyata. Daya konsumsi tertinggi terdapat pada perlakuan dengan pakan larva $O$. rhinoceros L instar 1 yaitu 130,17 ekor dan diikuti oleh perlakuan dengan pakan larva O. rhinoceros L instar 2 yaitu 108,17 ekor. Sedangkan daya konsumsi terendah terdapat pada perlakuan dengan pakan larva $O$. rhinoceros L instar 3 yaitu 73,83 ekor. Hal ini dikarenakan pada instar satu dan dua kulit 
kutikula larva masih lebih tipis dibandingkan dengan perlakuan instar tiga sehingga memudahkan semut untuk merobek kulit larva dan menghisap cairan haemolimfnya hingga habis. Hal ini sesuai dengan pernyataan Marheni (2012) yang menyatakan bahwa semut $M y$. castaneae lebih berpotensi memangsa larva instar dua daripada memangsa larva instar tiga, hal ini disebabkan kulit larva instar tiga lebih keras dibandingkan larva lnstar dua.

\section{Morfologi Anggota Semut $M y$. castaneae yang Dihasilkan}

Dari hasil pengamatan morfologi yang dilakukan didapatkan tiga jenis anggota semut yaitu semut ratu (Gambar 1a), semut jantan (Gambar 1b) dan semut pekerja (Gambar 1c).

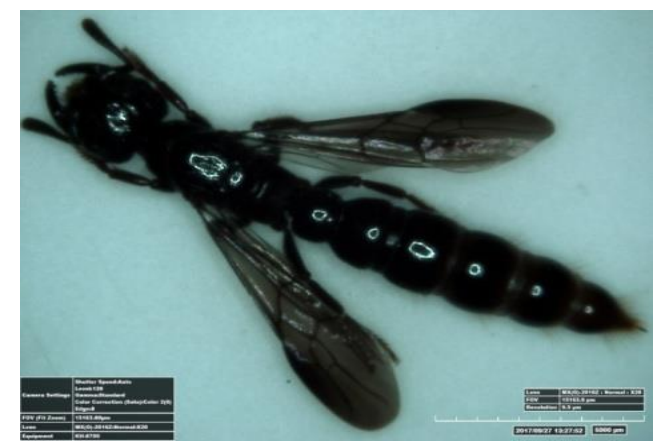

(a)

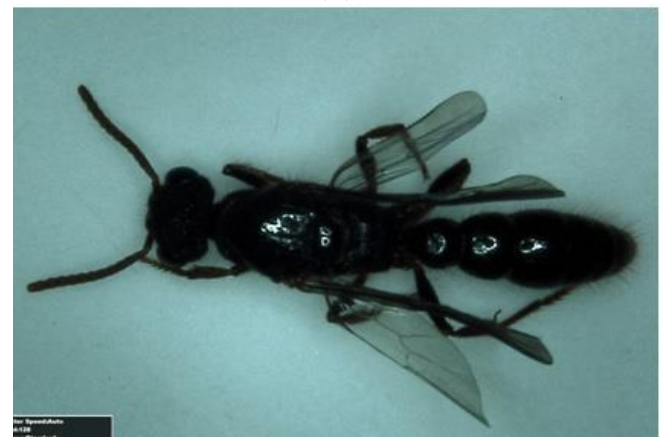

(b)

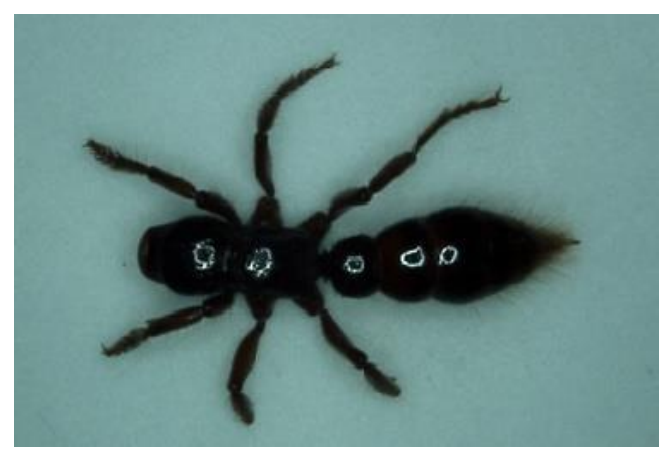

(c)
Gambar 1. Morfologi anggota semut My. castaneae yang dihasilkan (a) Ratu (b) Jantan (c) Pekerja

Semut ratu memiliki ukuran tubuh yang lebih besar dibanding semut lain. Panjang semut ratu yaitu $14,84 \mathrm{~mm}$. Semut ratu memiliki mekanisme terbang yang telah berkembang sejak memasuki fase imago. Semut ratu lebih banyak ditemukan pada musim penghujan dibandingkan musim kemarau. Hal ini dikarenakan pada musim penghujan banyak tersedia sumber makanan. Hal ini sesuai dengan Male dan Cuc (2004) yang menyatakan bahwa semut ratu banyak ditemukan pada musim penghujan karena banyak tersedia sumber makanan dan tanaman untuk membuat sarang sehingga mendukung untuk pertumbuhan koloninya.

Semut jantan berukuran lebih kecil daripada semut ratu. Panjang semut jantan yaitu 10,23 mm. Semut jantan juga memiliki mekanisme terbang yang telah berkembang sejak memasuki fase imago. Jumlah semut jantan lebih banyak daripada semut ratu. Semut jantan biasanya akan mati setelah melakukan perkawinan dengan semut ratu. Suhara (2009) menyatakan bahwa semut jantan hanya diproduksi pada saat-saat tertentu dalam satu tahun yaitu pada musim kawin dan setelah melakukan perkawinan dengan ratu biasanya semut jantan akan mati. Semut pekerja memiliki ciri-ciri yang mudah dikenal. Panjangnya yaitu 8,23- 9,96 mm. Tubuh ramping berwarna coklat kehitaman. Semakin tua semut pekerja maka warnanya juga semakin gelap. Mekanisme terbangnya tidak pernah berkembang (tidak memiliki sayap). Hal ini sesuai dengan Masuko (2013) yang menyatakan bahwa semut jantan dan semut betina pada umumnya adalah bersayap sementara itu semut pekerja tidak bersayap.

Dari hasil pengamatan morfologi semut didapatkan tiga jenis anggota semut yaitu semut ratu, semut jantan dan semut pekerja. Semut ratu dan semut jantan memiliki sayap sedangkan semut pekerja tidak memiliki sayap. Rizali (2016) menyatakan semut jantan dan semut betina pada umumnya bersayap sementara itu semut pekerja tidak bersayap. Ratu semut mempunyai abdomen yang besar dan 
pekerjaannya hanya bertelur untuk menjaga keturunannya, sementara itu semut pekerja terdiri dari semut-semut betina yang mandul. Tubuh semut terdiri atas tiga bagian yaitu caput, abdomen dan thorax. Caput secara keseluruhan terlihat luas. Sisi lateral sedikit cembung. Anterior lurus. Mandibel sempit dan terlihat jelas. Antena untuk semut ratu dan semut pekerja pendek dan kokoh sedangkan untuk semut jantan antena panjang. Antena bertipe geniculate yaitu ruas pertama memanjang dan ruas berikutnya pendek-pendek. Mata ocelli ada 3 ditengah dan masing-masing sisi lateral. Mata faset berada tepat di belakang garis tengah caput. Abdomen berwarna coklat kemerahan. Pada semut ratu terdiri atas 6 ruas, semut jantan 5 ruas dan semut pekerja 4-6 ruas. Pada abdomen, segmen basal sangat menonjol, segmen kedua dan berikutnya hampir serupa, apeksnya runcing terdapat rambut halus berwarna coklat. Pada semut ratu dan semut jantan terdapat dua pasang sayap seperti selaput. Sayap bagian depan lebih besar dari sayap bagian belakang. Pada semut jantan sayap belakang terlihat lebih tipis dan transparan. Sayap terdiri atas costa, subcosta, radius, media, humerial, sectorial, cubitalanal, radial serta medial. Tungkai semut memiliki tipe ambulatorial yaitu tungkai yang digunakan untuk berjalan dan berlari. Setiap tungkai terdiri atas coxa, femur, tibia, tarsus dan pretarsus yang terdiri atas lima ruas dan berakhir dengan sepasang kuku (claw). Warna tungkai coklat dan semakin tua semut semakin gelap. Hashimoto dan Rahman (2013) menyatakan ciri-ciri semut pada bagian caput terdapat banyak organ sensor, diantaranya adalah antena, antenal scrobe, mata, clypeus, frontal carina, mandibula dan palp formula. Thorax terdiri dari tiga segmen thorax yaitu; prothorax, mesothorax dan metathorax. Thorax juga merupakan tempat melekatnya (bersambungnya) kaki dan sayap. Abdomen pada semut terdiri dari tujuh buah segmen. Segmen abdomen yang pertama adalah propodeum yang tereduksi dan menyatu dengan thorax, segmen yang kedua adalah petiole, segmen yang ketiga atau yang keempat sampai yang ketujuh disebut dengan gaster.

\section{SIMPULAN}

Jumlah semut yang dihasilkan tertinggi adalah perlakuan instar I yaitu semut ratu 0,67 ekor, semut jantan 2,17 ekor dan semut pekerja 68,00 ekor. Daya konsumsi semut My. castaneae terhadap larva $O$. rhinoceros L. tertinggi pada perlakuan instar I yaitu 130,17 ekor. Semut yang dihasilkan ada tiga jenis yaitu semut ratu, semut jantan dan semut pekerja.

\section{DAFTAR PUSTAKA}

BPKKS. 2014. Buku Pedoman Kerja Kelapa Sawit. PTPN II NUSANTARA, Medan.

Chong, K. K. 2011. Crop Pest And Their Management In Malaysia, Tropical Press Sdn. Kuala lumpur, Malaysia

Hagen KS. 2016. Nutrition of entomophagous insects and other arthropods. Di dalam: Bellows TS, Fisher TW, editor. Handbook of Biological Control Principles and Application of Biological Control. California: Academic Press.

Hashimoto, Y \& H. Rahman. 2013. Inventory $\&$ Collection Total Protocol for Understanding of Biodiversity. Research and Education Component BBEC Programme. Sabah.

Junaedi, D. 2014. Daya Predasi Semut Myopopone castaneae (Hymenoptera :Formicidae) Terhadap Larva Penggerek Pucuk Kelapa Sawit Oryctes rhinoceros L. (Coleoptera : Scarabaidae) di Laboratorium. Skripsi. Program Studi Agroekoteknologi. Fakultas Pertanian. Universitas Sumatera Utara.

Lumbangaol, A. 2007. Pengaruh Pengunaan Tandan Kosong Kelapa Sawit dan Pupuk Mutiara sebagai Pupuk Organik Pada Tanaman Mentimun 
(Cucumis sativus L.). Universitas Islam Negeri Sumatera Utara. Medan.

Marheni. 2012. Eksplorasi Musuh Alami Oryctes rhinoceros L. pada Pertanaman Kelapa Sawit di Sumatera Utara. Laporan Akhir Kegiatan Penelitian Hibah Disertasi. Lembaga Peneliian dan Pengabdian Kepada Masyarakat UGM, Yogyakarta.

Masuko, K. 2013. Analysis of brood development in the ant Amblyopone silvestrii with special reference to colony bionomics. Institute of Natural Sciences, Senshu University, Kawasaki, Kanagawa, Japan. www. Google.com. Diakses 20 Februari 2017.

Noprida, 2009. Ekologi Pengendalian Hama Pada Tanaman Kelapa Sawit. Makalah Seminar Dan Pameran Ilmiah Himpunan Mahasiswa Hama dan Penyakit Tumbuhan UISU, Medan.

Oka, I.N. 2015. Pengendalian Hama Terpadu dan Implementasinya Di Indonesia. Gadjah Mada University press : Yogyakarta.

Purba, Y.R. 2010. Pemanfaatan Tandan Kosong Sawit Sebagai Perangkap O.rhinoceros (L.) Di Perkebunan Kelapa Sawit. Jurnal Penelitian Kelapa Sawit. http//:www.google.com. Diakses tanggal 20 Februari 2017.

Rizali, A. 2016. Keanekaragaman Semut di Kepulauan Seribu, Indonesia. Tesis. Program Studi Entomologi dan Fitopatologi. Institut Pertanian Bogor. 66 hal.

Sasromarsono, S. 2010. Keanekaragaman Hayati Arthropoda: Predator dan Parasit di Indonesia dan Pemanfaatannya. http//:www.Google.com. diakses tanggal 20 Februari 2017.

Suhara. 2009. Semut rangrang (Oecophylla smaragdina). Jurusan Pendidikan Biologi. Fakultas Pendidikan
Matematika dan Ilmu Pengetahuan Alam. Universitas Pendidikan Indonesia.

Susilo, 2007. Pengendalian Hayati dengan Memberdayakan Musuh Alami Hama Tanaman. Graha ilmu: Yogyakarta.

Widihastuty, M.C. Tobing, Marheni dan R.A. Kuswardani. 2017. Kemampuan Memangsa Semut Myopopone castaneae (Hymenoptera:

Formicidae) Terhadap Larva Oryctes rhinoceros Linn (Coleoptera: Scarabidae). Jurnal Ilmiah Simantek 1(4) (2017). 